Н. В. Шевченко, С. М. Кузнецов, А. Д. Дармаев [и др.]. Трудности диагностики инфаркта миокарда при атипичной грудной боли

\author{
Научная статья \\ УДК 616.127-005.8 \\ DOI: $10.18101 / 2306-1995-2021-1-9-19$

\section{ТРУДНОСТИ ДИАГНОСТИКИ ИНФАРКТА МИОКАРДА ПРИ АТИПИЧНОЙ ГРУДНОЙ БОЛИ}

Шевченко Н. В., Кузнецов С. М., Дармаев А. Д., Борисенко А. В., Онищук Ю. В., Таргашина Т. Б., Кудрин В. Б., Дунгуров О. Ц., Грязнов М. А., Штуккерт В. В., Цыремпилов Б.Б., Румянцева А. В., Сморкалова Н. В., Семенова Я. Р., Суфианова Е. О., Струнова-Лескова В. В.

\title{
(C) Шевченко Николай Васильевич
}

организатор здравоохранения, подполковник медицинской службы, начальник elenabotoeva@list.ru

\section{(C) Кузнецов Сергей Миронович}

врач-хирург высшей категории, заведующий операционным отделением s.m.kusnetzov@yandex.ru

\section{(C) Дармаев Андрей Дашиевич} врач-невролог высшей категории darmaevad@mail.ru

\section{(C) Борисенко Анастасия Викторовна}

врач-терапевт, заведующая приемным отделением nastaboris@mail.ru

\section{(C) Онищук Юлия Владимировна}

врач-терапевт, начальник приемного отделения onishchuk.y@inhox.ru

\section{(C) Таргашина Татьяна Борисовна}

врач-терапевт терапевтического отделения targashina.t@mail.ru

\section{(C) Кудрин Владимир Борисович}

врач-терапевт высшей категории, заведующий госпитальным отделением vladimir-kudrin@bk.ru

\section{(C) Дунгуров Олег Цыренович}

врач-терапевт, начальник поликлиники odungurov@bkl.ru

\section{(C) Грязнов Михаил Александрович} врач-терапевт, начальник терапевтического отделения войсковой части 46200 fybits@rambler.ru 
(C) Штуккерт Вячеслав Викторович

капитан медицинской службы, врач-инфекционист, старший ординатор инфекционного отделения work1box8@mail.ru

\section{(C) Цыремпилов Баир Бимбаевич}

капитан медицинской службы, начальник терапевтического отделения baik-baikal@mail.ru

\section{(C) Румянцева Анжела Викторовна}

врач-терапевт терапевтического отделения rumyan1971@mail.ru

\section{(C) Сморкалова Наталья Владимировна}

заведующая лабораторным отделением

nataliasmorkalova@yandex.ru

\section{(C) Семенова Яна Рудольфовна}

заведующая кабинетом функциональной диагностики yanarusem@gmail.com

\section{(C) Суфианова Елена Олеговна}

врач функциональной диагностики Suflenka@gmail.com

\section{(C) Струнова-Лескова Валентина Владимировна}

врач клинической лаборатории

valentinastrunova-leskova@yndex.ru

Филиал № 1 ФГКУ «425 ВГ» МО РФ

Россия, 664009, г. Иркутск, ул. Госпитальная, 1

Аннотация. От сердечно-сосудистых заболеваний в мире ежегодно умирает около 12 млн человек. Большинство этих случаев смерти связано с инфарктом миокарда. Половина больных умирает на догоспитальном этапе. Госпитальная смертность составляет в среднем около $10 \%$, еще около $10 \%$ больных с инфарктом умирает в течение года. Качество догоспитальной диагностики инфаркта миокарда остается серьезной проблемой. Одной из объективных причин этих ошибок является атипичная клиническая картина заболевания, где в $25 \%$ случаев течение инфаркта миокарда не укладывается в традиционные каноны. Она носит атипичный характер, значительно усложняя дифференциальную диагностику. В диагностике инфаркта миокарда важную роль играют не только качественный сбор анамнез болезни, тщательный осмотр пациента, но и применение основных, доступных и современных дополнительных методик. Мы приводим два клинических наблюдения атипичного клинического течения инфаркта миокарда. У пациента 42 лет с атипичным болевым синдромом, снимаемым спазмалгоном и раздражающими мазями, при углубленном обследовании диагностирован инфаркт миокарда. Во втором наблюдении пациент 23 лет, злоупотребляющий психонаркотическими препаратами, поступил с явлениями диспепсии, только тщательное обследование позволило выявить инфаркт миокарда.

Ключевые слова: инфаркт миокарда, атипичное течение, углубленная диагностика 
Н. В. Шевченко, С. М. Кузнеиов, А. Д. Дармаев [и др.]. Трудности диагностики инфаркта миокарда при атипичной грудной боли

\section{Для цитирования}

Трудности диагностики инфаркта миокарда при атипичной грудной боли / Н. В. Шевченко, С. М. Кузнецов, А. Д. Дармаев [и др.] // Вестник Бурятского государственного университета. Медицина и фармация. 2021. № 1. С. 9-19.

Прошло почти 250 лет, как В. Геберден (William Heberden) установил особую клиническую картину, названную им грудная жаба (anginapectoris). Перечисленные Геберденом симптомы описывались еще с античных времен. Но именно он выделил данный синдром в отдельную болезнетворную форму и дал ему название. Кроме того, он описал иррадиацию болей в левую руку, случаи внезапной смерти во время приступа. В настоящее время к признакам типичной стенокардии напряжения (anginapectoris) принято относить:

1) боль в области грудины, возможно с иррадиацией в левую руку, спину или нижнюю челюсть, длительность 2-5 мин. Эквивалентами боли бывают одышка, ощущение «тяжести», «жжения»;

2) вышеописанная боль возникает во время сильного эмоционального стресса или физической нагрузки;

3) такая боль быстро исчезает после прекращения физической нагрузки либо после приема нитроглицерина.

Встречаются атипичные варианты иррадиации боли (в эпигастральную область, лопатку, правую половину грудной клетки) [1-4; 6; 8].

Атипичная боль может иррадиировать в правое плечо, оба плеча или обе руки. «Еще реже боль может иррадиировать в середину спины, эпигастральную область и низ живота. В редких случаях стенокардии отмечалась иррадиация болей в левую половину поясницы и левую часть живота $[8 ; 11 ; 12]$.

Начало всех инфарктов миокарда обычно укладывается в шесть типов:

1) загрудино-болевой

2) периферический

3) абдоминальный

4) церебральный

5) безболевой

6) комбинированный

Загрудино-болевой - это «классический» тип, остальные типы имеют атипичную форму клинического проявления стенокардии или начала инфаркта миокарда:

а) периферический тип: леволопаточная; леворучная; верхнепозвоночная; нижнечелюстная; ушная; гортанно-глоточная; абдоминальная форма;

б) абдоминальный тип: приступ стенокардии и инфаркта миокарда начинается с острой брюшной катастрофы или воспалительного заболевания органов брюшной полости;

в) церебральный тип: обморочная форма, замаскированная под гипертонический криз, - начало клиники инфаркта миокарда, «токсикоинфекционная» (или «гастритическая») форма, гемиплегическая форма;

г) безболевой тип: астматическая форма, форма быстро наступающей тотальной сердечной недостаточности, коллаптоидная форма, аритмическая форма; 
д) комбинированный тип: например, церебрально-абдоминальный и т. д. ${ }^{1}$ [9; 12].

Боль - классический, но не единственный симптом ишемической болезни сердца (ИБС), в частности стенокардии. Во многих случаях одновременно с болью отмечаются тошнота, головокружение, общая слабость, отрыжка, изжога, диффузное или локальное потоотделение, затрудненное дыхание. Перечисленные симптомы и признаки нередко сопутствуют боли, а иногда выступают вместо нее $[5 ; 9]$.

Поэтому при опросе для выявления стенокардии неправильно использовать только слово «боль», следует обязательно уточнять наличие каких-либо неприятных ощущений, возникновение которых связано с эмоциональной или физической нагрузкой.

В нашей клинической практике было два подобных случая, которые мы приводим. Клиническое наблюдение 1: Военнослужащий (42 года) самостоятельно обратился в приемное отделение 16.07.2018 г. в связи с предъявляемыми жалобами на беспричинные, периодические ноющие боли в области второго межреберья, справа от грудины, которые купировались приемом спазмалгона два раза в день и втиранием согревающей мази в течение трех последних дней. Вышеуказанные боли не были связаны с физической нагрузкой; в целом чувствовал себя вполне удовлетворительно; общей слабости, утомляемости пациент не отмечал.

В анамнезе: в течение последних 10 лет отмечает повышение АД, дважды, стационарно в 2016-2017 гг., диагностировалась гипертоническая болезнь первой стадии. Назначенную гипотензивную терапию регулярно не принимал; эпизодически при повышении АД выше 140/90 мм рт. ст. принимал эналаприл по 5 мГ в сутки.

Объективно: состояние удовлетворительное. Границы сердца в норме, тоны приглушены, ритмичные. АД - 120/70 мм рт. ст. Пульс - 80 уд/мин. В остальном общесоматический статус без особенностей.

На ЭКГ — признаки поражения в передне-перегородочной стенке левого желудочка. Биохимический анализ крови от 26.07.2018 г.: положительный тропониновый тест. Фибриноген - 4,3 г/л, общий холестерин - 5,75 ммоль/л. ИХА-МФМ-МВ - положительный; в остальном биохимический анализ и общеклинический анализ крови в норме. В срочном порядке бригадой скорой медицинской помощи пациент переведен 16.07.2018 г. в ОГБУЗ «Иркутская областная клиническая больница», где была проведена коронарография с выявлением окклюзии правой коронарной артерии на $50 \%$, назначена соответствующая терапия. После выписки из ОКБ пациент продолжил лечение в терапевтическом отделении госпиталя с последующим переводом в санаторий для реабилитации. В сентябре 2018 г. в 3 ЦВКГ Вишневского (г. Москва) выполнена баллонная агиопластика со стентированием ПМЖА. После прохождения реабилитации чувствовал себя удовлетворительно.

${ }^{1}$ Горбачева С. М., Салато О. В. «Боль в грудной клетке» на догоспитальном этапе (Обзор литературы). 1 ГБОУ ДПО «Иркутская государственная академия последипломного образования» Минздравсоцразвития РФ (Иркутск). 2. Научный центр реконструктивной и восстановительной хирургии СО РАМН (Иркутск).

2 Там же. 
Н. В. Шевченко, С. М. Кузнеиов, А. Д. Дармаев [и др.]. Трудности диагностики инфаркта миокарда при атипичной грудной боли

Постоянно принимает гипотензивные препараты, антиагреганты, статины. В январе 2019 г. уволен по состоянию здоровья из Вооруженных Сил РФ.

Диагноз при увольнении 13.11.2018 г.: ишемическая болезнь сердца. Стабильная стенокардия напряжения III ФК. Постинфарктный (16.07.2018 г.) кардиосклероз. Тромболизис 17.07.2018 г. Стенозирующий атеросклероз коронарных артерий: ПМЖВ - стеноз устья и проксимальной трети $70 \%$. Операция: транслюминальная баллонная ангиопластика со стентированием ПМДА 14.09.2018 г. Хроническая сердечная недостаточность первой стадии, второго функционального класса. Гипертоническая болезнь третьей стадии, артериальная гипертензия второй степени со значительным нарушением функции «органов мишени».

ЭКГ 31.10.2018 г. PR - 144, QRS - 80, QT/QTc - 370/413, P-R-Taxes 43-48-52, синусовый ритм - 75 уд. в мин. Парциальный синдром предвозбуждения желудочков. СРРЖ 01.11.2018 г. PR - 156, QRS - 82, QT/QTc - 346/389, P-R-Taxes 48-51-52, синусовый ритм - 76-81 уд. в мин. ЭХО КГ 10.09.2018 г.: ТМЖП - 1,1 см, ТЗС - 1,1 см, КДР ЛЖ - 4,9 см, КСР ЛЖ - 3,5 см, КДО 112,8 мл, КСО - 50,9 мл, УО - 61,9 мл, ФВ - 64\%, МО - 4,7 л/мин, ММЛЖ 204,3 г, ИММЛЖ - 110,3 г/м². Умеренная гипокинезия миокарда верхушечного сегмента межжелудочковой перегородки. Фиброз створки аортального клапана. Фиброз створок и хорд митрального клапана, пролапс его передней створки 5 мм. Митральная регургитация 1-2 степени. Трикуспидальная регургитация 1-й степени. Регургитация на клапане легочной артерии 1-й степени. СДЛА -25 мм рт. ст. Признаки нарушения диастолической функции левого желудочка. ФВ ЛЖ - 55\%. Велоэргометрия от 21.09.2018 г.: проба завершена на 2-й ступени (50 Вт) из-за одышки, жалоб на головную боль. Проба проведена на фоне медикаментозной терапии. Реакция АД и ЧСС на нагрузку адекватная. ЧСС - 87-111-82. АД - 110/60-130/80-100/60 мм рт. ст. Диагностически значимого смещения сегмента ST не выявлено, нарушение ритма сердца не зарегистрировано. Толерантность к физической нагрузке низкая. Проба не завершенная. Тест с 6-минутной ходьбой 01.11.2018 г. исходно АД - 110/70 мм рт. ст. Пройдено 435 м, одышка на 4 минуте, жалобы на мелкую усталость. ЭКГ - без динамики. СМАД (на фоне гипотензивной терапии) 02.11.2018 г. № SB102: дневные часы: среднее САД понижено (121 мм рт. ст.). Средняя ЧСС - 76 уд/мин, максимальное АД - 130 (07:34)/100 (08:49) мм рт. ст. Ночные часы: среднее САД в норме (98 мм рт. ст.), среднее ДАД в норме (59 мм рт. ст.): вариабельность САД - высокое, средняя ЧСС 76 уд/мин, максимальное АД-140/89 (01:01) мм рт. ст. Суточный ритм АД нарушен по типу недостаточного ночного снижения САД. Все показатели утренней динамики повышены, кроме нормальной величины утреннего подъема САД. Коронарография 07.09.2018 г.: на серии коронарограмм определяется: ствол ЛКА - не изменен; ПМЖВ - протяженный стеноз устья и проксимальный трети 70-80\%; ДВ - не изменена; ОВ - не изменена; ВТК — не изменена; ПКА слаборазвита, не изменена; ЗМЖВ - не изменена; Левый тип коронарного кровоснабжения.

Клиническое наблюдение 2: Пациент К., 23 года, военнослужащий, доставлен в приемный покой с жалобами на боли в эпигастрии, горечь во рту, тошноту и рвоту, которые появились вечером и самостоятельно не проходили. Накануне, 
около 18 часов, появились боли в эпигастрии и за грудиной, без иррадиации, присоединилось чувство жара, повышение температуры до $37,5^{\circ} \mathrm{C}$. Беспокоили сердцебиение, тошнота, двукратная рвота, сначала водой, затем накануне съеденной пищей. Через 8 часов рвота желчью, без облегчения. Осмотрен дежурным врачом и дежурным хирургом, который исключил острую хирургическую патологию. Настораживала некоторая возбужденность и суетливость пациента. Госпитализирован в терапевтическое отделение для дообследования и определения тактики лечения с диагнозом: функциональная диспепсия. В процессе обследования, на 3-и сутки, были выявлены положительные маркеры некроза миокарда с изменениями на ЭКГ в виде патологического зубца q1, aVL в боковых отделах левого желудочка. Установлен диагноз: острый коронарный синдром, больной был переведен в кардиологическое отделение МСЧ ИАПО г. Иркутска. При дообследовании в моче были обнаружены фенотиазины, барбитураты, ДОЭТ (амфетамин). Верифицирован инфаркт миокарда без достоверного подъема сегмента $\mathrm{ST}$, без зубца Q, верхушечно-боковой, нижней и задней стенки ЛЖ токсического генеза. Проводилось лечение: наркотические анальгетики, в/в инфузии нитратов, антикоагулянты, дезагреганты, антагонисты кальция, ß-блокаторы, омепразол. После стабилизации состояния пациент вновь переведен в терапевтическое отделение госпиталя. Состояние больного удовлетворительное (ИМТ - 26,4). Кожные покровы чистые, периферические л/узлы и щитовидная железа не увеличены. Костно-мышечная система и связочно-суставной аппарат без видимой патологии. Дыхание везикулярное, хрипов нет, ЧДД - 18 в 1 минуту. Тоны сердца приглушены, ритмичные; границы в норме. АД - 120/70 мм рт. ст., пульс - 76 в 1 минуту. Язык влажный, чистый. Живот мягкий, безболезненный. Печень, селезенка не увеличены. Поколачивание по поясничной области безболезненное. Физиологические отправления в норме. Неврологический статус без особенностей. ЭКГ — признаки Q-негативного инфаркта миокарда с локализацией в передней перегородочной, верхушечной, нижнебоковой стенках левого желудочка, подострый период, закономерная динамика. Холтер ЭКГ синусовый ритм со средней ЧСС - 69 в минуту, максимальная ЧСС - 116 в минуту, минимальная ЧСС 49 в минуту. Зарегистрированы 10 желудочковых экстрасистол, 2 куплета, 1 триплет, 4 предсердных экстрасистол. $S T$ событий по ишемическому типу нет. Длительное применение высоких доз вызывает серьезное нарушение психической деятельности, а также повышает риск развития сердечно-сосудистых заболеваний. Длительный прием производных фенотиазина в сочетании с барбитуратами приводит к постоянной ишемии миокарда. Таким образом, все три найденных вещества у данного пациента могли привести к развитию инфаркта миокарда, что и отмечено в диагнозе (инфаркт миокарда токсического генеза) [8; 10-12; 15; $17 ; 18 ; 21 ; 27 ; 31]$. Отмеченная дежурным врачом и хирургом некоторая суетливость и возбужденность должна была натолкнуть на мысль о неадекватном психическом состоянии больного, которое было возможно после приема вышеуказанных средств.

Пациент выписан в удовлетворительном состоянии с рекомендацией прохождения освидетельствования в госпитале Н. Н. Бурденко (Москва).

\section{Выводы}

1. Болевой синдром при инфаркте миокарда у 1-го больного характеризовался в нетипичном месте. 
Н. В. Шевченко, С. М. Кузнеиов, А. Д. Дармаев [и др.]. Трудности диагностики инфаркта миокарда при атипичной грудной боли

2. Прием спазмалгона и согревающих мазей (во втором межреберье справа от грудины) в первом клиническом наблюдении, возможно, маскировал клиническую картину атипичного болевого синдрома при инфаркте миокарда.

3. Нерегулярный прием пациентом гипотензивной терапии, вероятно, способствовал развитию острого инфаркта миокарда, так как повышенные уровни АД имеют прямую и независимую связь с частотой развития большинства сердечно-сосудистых событий (в том числе инфаркта миокарда).

4. Инфаркт миокарда во втором клиническом наблюдении был спровоцирован, вероятнее всего, приемом наркотических и снотворных средств (фенотиазина, барбитуратов и ДОЭТ (амфетамина), обнаруженных в крови пациента). Амфетамин - распространенный наркотик, мощный стимулятор ЦНС и эйфоретик. Во всех неясных случаях торакальных и абдоминальных болей необходимо сделать ЭКГ пациенту.

5. Дополнительное исследование крови и мочи у 2-го больного позволило выявить наркотические вещества, которые явились причиной развития инфаркта миокарда.

\section{Литература}

1. Абдрахманова А. И. Атипичные формы инфаркта миокарда с подъемом сегмента ST // Сборник материалов X Национального конгресса терапевтов (Москва, 14-16 октября 2015 г.). Москва, 2015. С. 1. Текст: непосредственный.

2. Боль в груди в фокусе несердечные кардиалгии / А. А. Беляев, О. В. Котов, Е. С. Акарачкова, А. С. Артеменко. URL: medblog.ru (дата обращения: 09.06.2019). Текст: электронный.

3. Ведзижева М. Д. Терапевтическая эффективность полиоксидония и магнитоинфракрасного лазерного излучения при легкой бронхиальной астме у детей: диссертация на соискание ученой степени кандидата медицинских наук. Москва, 2008. Текст: непосредственный.

4. Видякина Н. В. Особенности клинического течения гастроэзофагеальнорефлюксной болезни в сочетании с ишемической болезнью сердца: автореферат диссертации на соискание ученой степени кандидата медицинских наук. Москва, 2009. 24 с. Текст: непосредственный.

5. Гапонова Н. И. Синдром кардиалогии при остеохондрозе грудного отдела позвоночника: диагностика и лечение ингибитором циклооксигеназы лорноксикамом: автореферат диссертации на соискание ученой степени кандидата медицинских наук. Москва, 2009. 24 с. Текст: непосредственный.

6. Гармаш В. А. Внутривенное лазерное облучение крови при гнойно-септических заболеваниях и травмах детей // Новое в лазерной медицине и хирургии: тезисы международной конференции. Переславль-Залесский, 1990. Ч. 1. С. 142-143. Текст: непосредственный.

7. Тактика врача скорой помощи при острых отравлениях новыми синтетическими наркотиками психостимулирующего действия / С. Ю. Грачев, Н. П. Новикова, А. Л. Суковатых [и др.] // Экстренная медицина. 2005. № 2. С. 112-119. Текст: непосредственный.

8. Давыденко В. В., Галилеева А. Н., Иванова О. П. Опыт внедрения инновационных методов лечения варикозной болезни вен нижних конечностей в условиях городской поликлиники // Материалы 5 съезда амбулатор. хир. Рос. Федерации. Санкт-Петербург, 2016. С. 42. Текст: непосредственный.

9. Трансмуральный инфаркт миокарда у молодых больных с неизмененными коронарными артериями, принимавших метадон / Д. Г. Иоселиани, С. П. Семитко, Д. Г. Гранов и [др.] // Кардиология (Kardiologiia). 2004. № 10. Текст: непосредственный. 
10. Мазуров В. И., Уланова В. И. Течение инфекционного эндокардита у инъекционных наркоманов и лиц с предраспологающими заболеваниями сердца // Клиническая медицина. 2001. № 8. С. 23-28. Текст: непосредственный.

11. Маслов С. В., Кцоева Т. В., Ковалев Ю. Р. Инфекционный эндокардит клапанов левых камер сердца инъекционных наркоманов // Клиническая медицина. 2002. № 3. С. 23-27. Текст: непосредственный.

12. Основные принципы применения лазерных систем в медицине / И. А. Михайлова, Г. В. Папаян [и др.]; под ред. Н. Н. Петрищева. Санкт-Петербург, 2007. 44 с. Текст: непосредственный.

13. Москвин С. В. Эффективность лазерной терапии. Сер. Эффективная лазерная терапия. Москва, 2014. Т. 2. 896 с. Текст: непосредственный.

14. Случай амфетаминового инфаркта миокарда у восемнадцатилетнего юноши / А. В. Мухин, Р. А. Разыграев, Д. В. Алексеев, В. Ф. Виноградов // Верхневолжский медицинский журнал. 2012. Т. 10, вып. 2. С. 25-29. Текст: непосредственный.

15. Лазерная терапия в педиатрии / С. В. Москвин [и др.]. Тверь: Триада, 2009. Текст: непосредственный.

16. Никифоров И. А. Сердечно-сосудистые расстройства при злоупотреблении психоактивными и наркотически действующими веществами // Российский кардиологический журнал. 2007. № 2(64). С. 98-105. Текст: непосредственный.

17. Никифоров И. А. Злоупотребление психоактивными веществами и сердечнососудистая патология // Профилактика заболеваний и укрепление здоровья. 2006. № 5. С. 41-47. Текст: непосредственный.

18. Неворотин А. И. Введение в лазерную хирургию. Санкт-Петербург: Спецлит, 2000 Текст: непосредственный.

19. Приезжаев А. В., Тучин В. В., Шубочкин Л. П. Лазерная диагностика в биологии и медицине. Москва: Наука, 1989. Текст: непосредственный.

20. Радзинская Е. В., Александрова М. Р., Политидис Р. Р. Инфекционный эндокардит у пациентов с инъекционной наркоманией // Вестник РУДН. Сер. Медицина. № 3. С. 106-111. Текст: непосредственный.

21. Загидуллин Н. Щ., Фахрутдинов У. Р. Синдром боли в грудной клетке: учебное пособие. Уфа: Изд-во БГМУ Минздрава России, 2016. 85 с. Текст: непосредственный.

22. Соколов А. Л. Лядов К. В., Луценко М. М. Лазерная облитерация вен для практических врачей. Москва: Мед. практика, 2011. 203 с. Текст: непосредственный.

23. Лазерный медицинский комплекс для лечения онкологический заболеваний «ЛИТТ-ФДТ» / А. Н. Солдатов, А. В. Гейниц, В. А. Етушенко [и др.] // Сибирский онкологический журнал. 2009. № 1, вып. 31. С. 51-55. Текст: непосредственный.

24. Сотников А. В. Клиническая характеристика и особенности течения инфаркта миокарда у лиц молодого и среднего возраста: диссертация на соискание ученой степени кандидата медицинских наук. 2007. Текст: непосредственный.

25. Странадко Е. Ф. Основные этапы развития и современное состояние фотодинамической терапии в России // Лазерная медицина. 2012. Т. 16, вып. 2. С. 4-14. Текст: непосредственный.

26. Супроненко И. М., Парцерняк А. С. Проблема клинического токсиколога: как своевременно дифференцировать токсическую миокардиодистрофию от инфаркта миокарда при остром отравлении наркотическими препаратами // Известия Российской военно-медицинской академии. 2018. Т. 37, № 1. Текст: непосредственный.

27. Хороших О. А. Атипичные варианты инфаркта миокарда. Клинический случай редкой формы острого коронарного синдрома с периферическим эквивалентом стенокардии // Бюллетень ВСНЦ СО РАМН. 2013. № 5(93). С. 104-107. Текст: непосредственный. 
Н. В. Шевченко, С. М. Кузнецов, А. Д. Дармаев [и др.]. Трудности диагностики инфаркта миокарда при атипичной грудной боли

28. Распространенность факторов риска сердечно-сосудистых заболеваний в российской популяции больных артериальной гипертонией / И. Е. Чазова [и др.] // Кардиология. 2014. № 10. С. 4-12. Текст: непосредственный.

29. Шиманко А. И., Дибиров М. Д., Волков А. С. Возможности использования комплекса хирургических методов лечения хронических заболеваний вен в амбулаторной практике // Славянский венозный форум: материалы международного конгресса. Витебск, 2015. С. 81. Текст: непосредственный.

30. Кокаин-индуцированный инфаркт миокарда: клинико-патогенетические особенности, лечение / Е. М. Яшина, Н. Г. Беляева, А. Н. Кузнецов, Е. А. Баранов // Медицинский альманах. 2011. № 3(16). Текст: непосредственный.

31. Last J. M. Dictionary of epidemiology. Oxford University Press New York: 2000.

32. Prevalence, clinical features, and acute course of atypical myocardial infarction / L. Lusiani [et al.]. 1994.

33. Prevalence, incidence, predictive factors and prognosis of silent myocardial infarction: A review of the literature / Paul Valensi [et al.]. 2011.

34. Supronenko I. M., Partsernyak A. S. The problem of a clinical toxicologist: how to differentiate toxic myocardiodystroghy from myocardial infarction in acute poisoning with narcotic drugs // S. M. Kirov Millitary Medical Akademy the Departament of Military Field Therapy.

35. A Computational Algorithm for Designing an Active Optical System with an Image Intensifier / M. V. Trigub, N. A. Agapov, G. S. Evtushenko, F. A. Gubarev // Russian Physics Journal. 2013 Vol. 56, №. 5. P. 588-591.

Статья поступила в редакичию 09.01.2021; одобрена после рецензирования 25.01.2021; принята к публикации 09.04.2021.

\section{DIFFICULTIES IN DIAGNOSING MYOCARDIAL \\ INFARCTION IN PATIENTS WITH ATYPICAL CHEST PAIN}

Shevchenko N. V., Kuznetsov S. M., Darmaev A. D., Borisenko A. V., Onischuk Yu. V., Targashina T. B., Kudrin V. B., Dungurov O. Ts., Gryaznov M. A., Shtukkert V. V., Tsyrempilov B. B., Rumyantseva A. V., Smorkalova N. V., Semenova Ya. R., Sufianova E. O., Strunova-Leskova V. V.

Nikolay V. Shevchenko

Health Official, Lieutenant Colonel of Medical Corps

elenabotoeva@list.ru

Sergey M. Kuznetsov

Board Certified in Surgery, Head of Surgical Unit

s.m.kusnetzov@yandex.ru

Andrey D. Darmaev

Board Certified in Neurology

darmaevad@mail.ru

Anastasia V. Borisenko

Internist, Head of Admission Unit

nastaboris@mail.ru 
Yulia V. Onischuk

Internist, Head of Admission Unit

onishchuk.y@inhox.ru

Tatyana B. Targashina

Internist of Internal Medicine Unit

targashina.t@mail.ru

Vladimir B. Kudrin

Board Certified in Internal Medicine, Head of Hospital Unit

vladimir-kudrin@bk.ru

Oleg Ts. Dungurov

Internist, Head of Polyclinic

odungurov@bkl.ru

Mikhail A. Gryaznov

Internist, Head of Internal Medicine Unit

fybits@rambler.ru

Vyacheslav V. Shtukkert

Captain of Medical Corps, Infectious Disease Doctor,

Senior Physician of Infectious Diseases Unit

work1box8@mail.ru

Bair B. Tsyrempilov

Captain of Medical Corps, Head of Internal Medicine Unit

baik-baikal@mail.ru

Anzhela V. Rumyantseva

Internist of Internal Medicine Unit

rumyan1971@mail.ru

Natalya V. Smorkalova

Head of Laboratory Unit

nataliasmorkalova@yandex.ru

Yana R. Semenova

Head of Functional Diagnostics Unit

yanarusem@gmail.com

Elena O. Sufianova

Functional Diagnostics Doctor

suflenka@gmail.com

Valentina V. Strunova-Leskova

Clinical Laboratory Physician

valentinastrunova-leskova@yndex.ru

Branch No. 1 of Federal State-Owned Institution "425 Military Hospital"

The Defence Ministry of the Russian Federation

1 Gospitalnaya St., Irkutsk 664009, Russia 
Abstract. About 12 million people die from cardiovascular diseases in the world every year. Most of these deaths are associated with myocardial infarction. Half of the patients die at the prehospital stage. Hospital mortality averages about $10 \%$, and the same number of patients with a heart attack dies within a year. The quality of pre-hospital diagnosis of myocardial infarction remains low. One of the objective causes of these errors is the atypical clinical picture of the disease: in $25 \%$ of cases the course of myocardial infarction does not fit into the traditional framework. Not only medical history and typical clinical manifestation play an important role in the diagnosing myocardial infarction, but also application of modern methods. The medical history and typical clinical manifestation play an important role in the diagnosing myocardial infarction. We have analyzed two cases of the atypical course of myocardial infarction. A 42-year-old patient with atypical pain syndrome reduced by spasmalgon and irritating ointments, was diagnosed with myocardial infarction during an indepth examination. In the second case, a 23 -year-old patient, abusing drugs, was admitted with symptoms of dyspepsia, only a thorough examination revealed myocardial infarction. Keywords: myocardial infarction, atypical disease course, in-depth diagnostics

\section{For citation}

Shevchenko N. V., Kuznetsov S. M., Darmaev A. D., et al. Difficulties in Diagnosing Myocardial Infarction in Patients with Atypical Chest Pain. Bulletin of Buryat State University. Medicine and Pharmacy. 2021; 1: 9-19 (In Russ.).

The article was submitted 09.01.2021; approved after reviewing 25.01.2021; accepted for publication 09.04.2021. 